\title{
Upgradation of Low-Grade Siliceous Manganese Ore from Bonai-Keonjhar Belt, Orissa, India
}

\author{
P.P. Mishra ${ }^{1}$, B.K. Mohapatra ${ }^{1}$, and K. Mahanta ${ }^{2}$ \\ ${ }^{1}$ Institute of Minerals and Materials Technology, Bhubaneswar \\ ${ }^{2}$ OMDC Ltd, Thakurani, Orissa
}

\begin{abstract}
The low-grade siliceous manganese ores from Bonai-Keonjhar belt, Orissa, India was mineralogically characterized and investigated for their possible upgradation. Different physical beneficiation techniques like gravity, magnetic separation etc. were employed and results reported. The results reveal that a feed having 26\% Mn could be upgraded to more than $45 \% \mathrm{Mn}$ by using a dry belt type magnetic separator with 69\% recovery at 1.00 tesla magnetic intensity at finer sizes.
\end{abstract}

\section{INTRODUCTION}

Orissa occupies a significant position in mineral map of India in general and manganese ores in particular. The manganese ore mineralization in Orissa is mainly confined to three stratigraphic horizons, out of which the ores of Iron ore group occupies a larger area and mostly occurs in the well-known horse shoe shaped belt of Banded Iron Formation of Precambrian age. The manganese ores are mostly low to medium grade type with low phosphorous content in contrast to the other manganese deposits in Orissa. Three varieties of low-grade Mn-ore such as a) siliceous, b) ferruginous and c) aluminous types have been reported from this belt ${ }^{(1)}$. Over the last few decades, selective mining of better grade manganese ores from this area has generated a huge quantity of low/off grade ores, which are considered as waste. Stacking of such ores near 
the mine site causes both land degradation and environmental pollution. Further, 5 lakh tones (2) of Mn-ore that is produced annually in Orissa, 50\% (2.5 lakh tonne) of it is of low-grade category (Mn: 25-35\%). Out of these low-grade Mn-ores, the siliceous variety occupies a sizeable volume ( 20\%). Stringent raw material specification issued by different industrial units using manganese further adds to the menace. Hence, suitable techniques for optimum utilization of these low/off grades ores need to be evolved so that valuable forest lands can be saved and remarkable values addition can be made.

With this objective the low/off grade siliceous manganese ores from Orissa Mineral Development Corporation (OMDC) lease hold in Bonai-Keonjhar belt of north Orissa, India was investigated. Different types of physical beneficiation techniques like gravity (tabling) and magnetic (dry magnetic and wet magnetic) methods were employed to upgrade these ores for proper utilization. The result of these investigations was reported in this paper.

\section{MATERIALS AND METHODS}

Around one tone of representative low-grade siliceous manganese ore sample was collected from Bhoot-River side lease-hold of M/s OMDC Ltd. Barbil, Orissa. All the samples were crushed to below $2 \mathrm{~mm}$ size by roll crusher at different gap settings and classified into different size fractions using standard test sieve viz. $2 \mathrm{~mm}, 1 \mathrm{~mm}, 0.5 \mathrm{~mm}, 0.25 \mathrm{~mm}, 0.15 \mathrm{~mm}$ and $0.075 \mathrm{~mm}$.

The mineralogical characterization was carried out using optical microscope (Letiz make) and Xray diffractometry (Philips make). Detail beneficiation studies were carried out using $1016 \mathrm{X}$ 437mm Denver Wilfley laboratory table supplied by M/s DENVER, U.S.A. For tabling studies the manganese ore was reduced to $-2.0 \mathrm{~mm}$ by stage crushing on roll crusher. The sample below $2.0 \mathrm{~mm}$ was ground in a ball mill to prepare $-0.5 \mathrm{~mm}$ sample by closed circuit grinding maintaining $250 \%$ circulating load. Further the ground sample was classified to $-500+150 \mu \mathrm{m}$ and $-150 \mu \mathrm{m}$. About $10 \mathrm{~kg}$ of sample from each fraction was mixed with 20 liters of water and made uniform slurry. This slurry is pumped to table feed box at uniform rate of $20 \mathrm{~kg} / \mathrm{hour}$. The wash water was maintained at 6 liter per minute and stroke length was kept at $10 \mathrm{~mm}$.

High intensity dry belt magnetic separator of type LOG 1.4 SEP operated at 50 Dc Volt and 4.17 Dc amp. current, suitable for fine particle separation, (supplied by Boxmag Rapid Ltd., Birmingham, England) was also employed. The magnetic intensity was varied between 0.73 and 1.23 tesla. Dry samples of closed size fractions were continuously fed to the belt magnetic separator by vibrating feeder at controlled rate $(6 \mathrm{rpm})$. Based on the requirement of size and intensity, feed rate, and gap between the belt and disc in the magnetic separator was varied.

For wet magnetic separation wet high intensity magnetic separator (WHIMS) supplied by M/s Box Mag Rapid, England was used. The magnetic intensity of the instrument was varied by 
varying the grid gaps and applied current. The Mn-containing slurry (with 25\% solid concentration) was first conditioned for 10 minutes and then passed through the magnetic separator in several batches. The magnetic fraction was retained in the grid and the non-magnetic fraction was collected at the bottom.

All the products obtained from each experiment were collected separately, dried, weighed and analyzed for $\mathrm{Mn}$, Fe and selected samples for $\mathrm{SiO}_{2}$.

\section{RESULTS AND INTERPRETATION}

\subsection{Mineralogical Characteristics}

X-ray diffraction and optical microscope studies were extensively undertaken for mineralogical characterization of low-grade siliceous Mn-ore. The ore exhibits two distinct textural peculiarities; a) large saccaroidal crystalline quartz with Mn infilling (Fig. 1a), b) fine granular quartz with Mn infilling (Fig. 1b). Hematite and Kaolinite in subordinate amount is recorded in granular variety. Pyrolusite and cryptomelane constitute two distinct Mn-phases and the quartz forms the dominant gangue mineral as revealed from their XRD pattern (Fig. 2). Pyrolusite occurs as large bladed crystals having sharp contact relationship with quartz (Fig. 3a), while thin veins of cryptomelane traverse through quartz (Fig. $3 \mathbf{b})$.
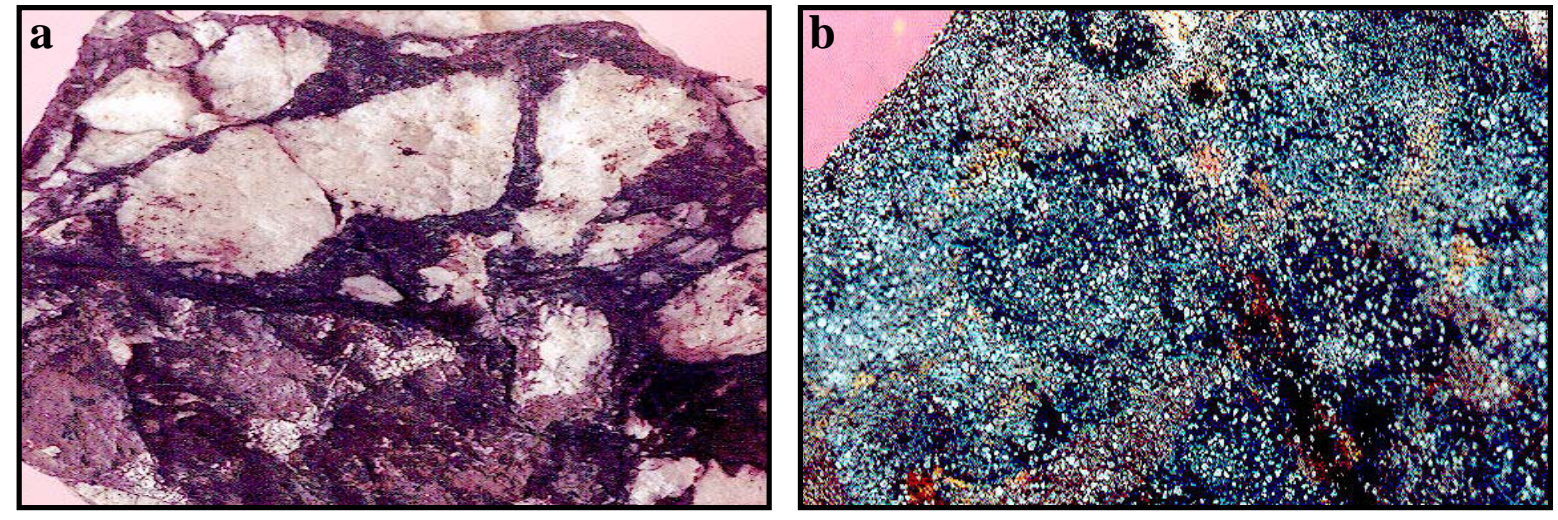

Fig.1: Microphotographs of low-grade siliceous Mn-ore

a. Manganese containing large pieces of saccaroidal quartz

b. Spotted manganese ore showing finely distributed quartz grains 


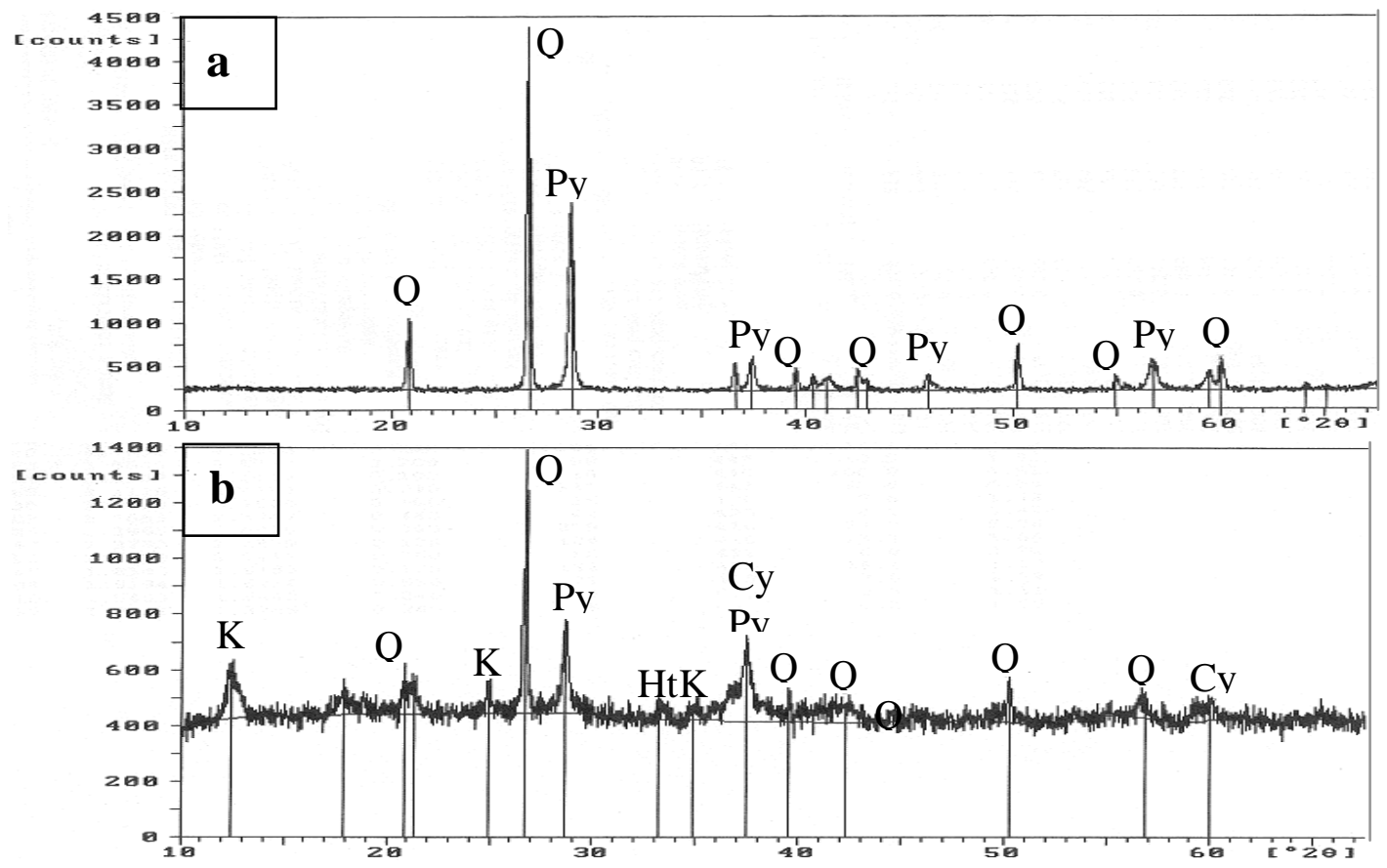

Fig. 2: X-ray diffraction pattern of low-grade siliceous Mn-ore

a. Siliceous Crystalline variety

b. Siliceous Saccaroidal variety
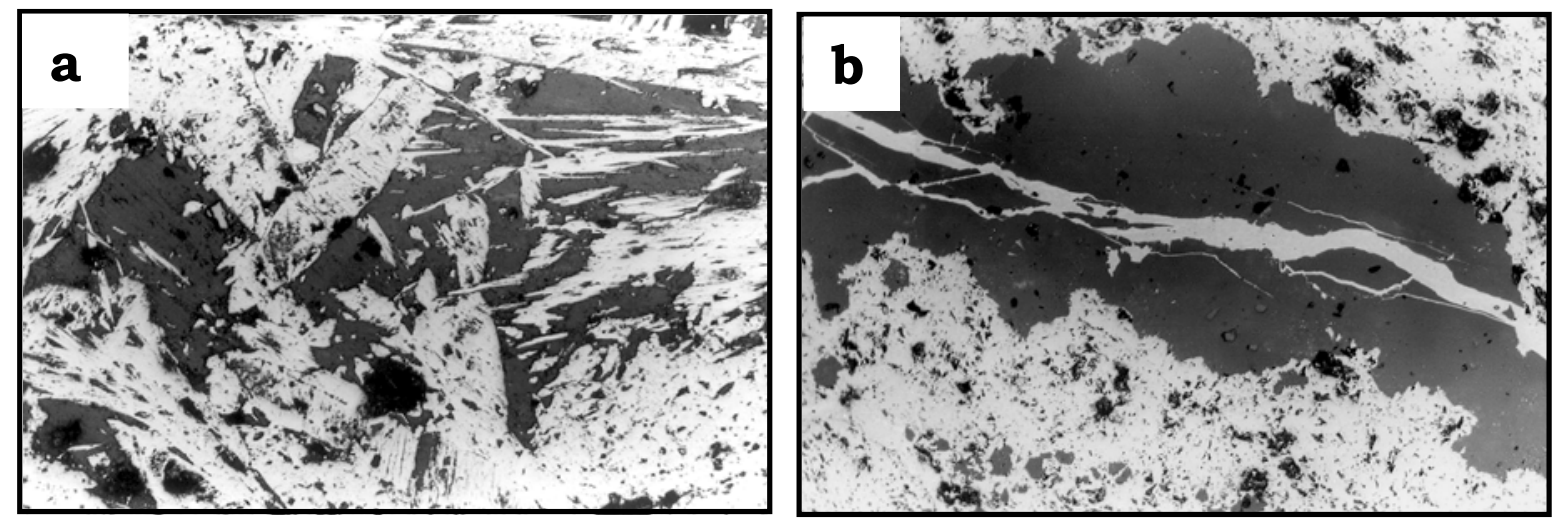

Fig. 3: Photomicrographs of manganese minerals showing different micro-texture x200

a. Coarsely crystalline pyrolusite replacing clayey material

b. Thin vein of cryptomelane traversing a clayey matrix (pyrolusite is present at top \& bottom) 


\subsection{Physical and Chemical characteristics}

The low-grade ROM sample was crushed and subjected to sieve analysis using standard test sieves of 1000, 500, 250, $150 \& 75 \mu \mathrm{m}$ size. Each fraction was weighed and analyzed for Mn, Fe and selected samples for $\mathrm{SiO}_{2}$. The results of the size and chemical analyses of bulk (considered as feed) and fractionated materials are shown in Table 1. It is clear from the table that both iron and manganese are almost uniformly distributed in all the size fractions.

Table 1. Size and chemical analysis of low-grade siliceous Mn-ore.

\begin{tabular}{|c|c|c|c|c|}
\hline Size in $\mu \mathrm{m}$ & $\mathrm{Wt} \%$ & $\mathrm{Mn} \%$ & $\mathrm{Fe} \%$ & $\mathrm{SiO}_{2} \%$ \\
\hline Bulk & - & 26.41 & 2.78 & 32.42 \\
\hline$-1000+500$ & 40.1 & 24.84 & 2.78 & 34.93 \\
\hline$-500+250$ & 33.4 & 25.47 & 2.92 & 33.78 \\
\hline$-250+150$ & 9.5 & 28.93 & 3.06 & 27.98 \\
\hline$-150+75$ & 9.4 & 28.93 & 3.06 & 27.49 \\
\hline-75 & 7.6 & 27.00 & 4.22 & 32.11 \\
\hline Head & 100 & 25.96 & 2.98 & 32.95 \\
\hline
\end{tabular}

\subsection{Beneficiation Characteristics}

In order to assess the upgradation potential of low-grade siliceous manganese ore the sample was subjected to different physical beneficiation techniques. Different beneficiation methods followed for upgradation are described below:

\subsection{Heavy Media Separation Studies}

The closed size samples were subjected to sink and float studies using bromoform (specific gravity 2.86) as medium. The results of the studies are presented in Table 2. Float and sink products in each case were analyzed for both $\mathrm{Mn} \& \mathrm{Fe}$. It may be seen from the table that $\mathrm{Mn}$ content in sink is increasing with decrease in size (up to -150+75 $\mu \mathrm{m}$ fraction), which indicates that better liberation is achieved at finer fractions. It is interesting to note that weight percent of sink are almost same in all the size fractions (64 to $65 \%$ ). It is also observed that Mn content in float fractions is only $2-3 \%$ by weight indicating that most of the gangue minerals are present in the liberated form.

\subsection{Tabling Studies}

Preliminary study on a mineral separator indicated that gravity technique can be adopted to recover most of Mn values in general but better recovery would be achieved below $500 \mu \mathrm{m}$. 
Hence, representative sample was ground to below $500 \mu \mathrm{m}$ size and classified into two fractions viz. $-500+150 \mu \mathrm{m} \&-150 \mu \mathrm{m}$. These fractions were subjected to tabling studies and results are shown in Table 3. These results indicate that a concentrate having $42 \% \mathrm{Mn}$ with $40 \%$ recovery can be obtained from the coarse fraction while finer fraction can give a product with $38.25 \% \mathrm{Mn}$ only.

Table 2. Results of sink and float studies.

\begin{tabular}{|c|c|c|c|c|c|}
\hline Size in micron & Nature & Wt \% & Mn \% & Fe \% & Mn \% Dist. \\
\hline \multirow{2}{*}{$-1000+500$} & Float & 35.38 & 2.51 & 0.69 & 3.6 \\
\cline { 2 - 6 } & Sink & 64.62 & 36.48 & 4.17 & 96.4 \\
\hline \multirow{2}{*}{$-500+250$} & Float & 35.66 & 2.20 & 1.11 & 2.9 \\
\cline { 2 - 6 } & Sink & 64.34 & 40.25 & 4.45 & 97.1 \\
\hline \multirow{2}{*}{$-250+150$} & Float & 35.28 & 1.25 & 1.67 & 1.60 \\
\cline { 2 - 6 } & Sink & 64.72 & 42.77 & 3.89 & 98.4 \\
\hline \multirow{2}{*}{$-150+75$} & Float & 34.22 & 2.67 & 1.39 & 3.0 \\
\cline { 2 - 6 } & Sink & 65.78 & 44.97 & 4.45 & 97.0 \\
\hline
\end{tabular}

Table 3. Results of tabling studies.

a) Tabling results of $-500+150 \mu \mathrm{m}$ sample

\begin{tabular}{|c|c|c|c|c|}
\hline Details & Wt. \% & Mn \% & Fe \% & Mn Rec. \% \\
\hline Concentrate & 21.1 & 42.05 & 4.34 & 40.7 \\
\hline Middling & 51.1 & 19.17 & 2.26 & 44.9 \\
\hline Tailing & 27.8 & 11.28 & 1.88 & 14.4 \\
\hline
\end{tabular}

b) Tabling results of $-150 \mu \mathrm{m}$ sample

\begin{tabular}{|c|c|c|c|c|}
\hline Details & Wt \% & Mn \% & Fe \% & Mn Rec. \% \\
\hline Concentrate & 18.0 & 38.25 & 3.89 & 26.4 \\
\hline Middling & 5.6 & 20.16 & 2.22 & 4.3 \\
\hline Tailing & 76.4 & 23.64 & 2.50 & 69.3 \\
\hline Head & 100.0 & 26.07 & 2.73 & 100 \\
\hline
\end{tabular}

\subsection{Dry Magnetic Separation}

All the size fractions were subjected to dry magnetic separation at different magnetic intensities viz. 0.73 tesla, 1.00 tesla and 1.23 tesla to assess its magnetic susceptibility. The magnetic 
products obtained at different magnetic intensities are presented in Table 4. It is observed from the table that on an average a product having $45 \% \mathrm{Mn}$ at $69 \%$ recovery can be obtained at 1.00 tesla for all the size fractions.

Table 4. Results of dry magnetic separation of dry sieving samples.

\begin{tabular}{|c|c|c|c|c|c|c|c|c|c|}
\hline & \multicolumn{3}{|c|}{$\mathbf{0 . 7 3}$ tesla } & \multicolumn{3}{c|}{1.00 tesla } & \multicolumn{3}{c|}{1.23 tesla } \\
\hline Size, in $\mu \mathrm{m}$ & Wt. \% & Mn \% & $\begin{array}{c}\text { Mn \% } \\
\text { recovery }\end{array}$ & $\begin{array}{c}\text { Wt. } \\
\%\end{array}$ & Mn \% & $\begin{array}{c}\text { Mn \% } \\
\text { recovery }\end{array}$ & $\begin{array}{c}\text { Wt. } \\
\%\end{array}$ & $\begin{array}{c}\text { Mn } \\
\%\end{array}$ & $\begin{array}{c}\text { Mn \% } \\
\text { recovery }\end{array}$ \\
\hline$-1000+500$ & 38.8 & 41.9 & 23.9 & 39.3 & 43.51 & 26.0 & 41.9 & 42.7 & 33.9 \\
\hline$-500+250$ & 33.0 & 44.7 & 21.7 & 32.8 & 45.91 & 23.0 & 32.6 & 44.6 & 27.5 \\
\hline$-250+150$ & 14.2 & 42.9 & 8.9 & 13.8 & 45.91 & 9.7 & 12.4 & 41.5 & 9.7 \\
\hline$-150+75$ & 14.0 & 46.4 & 9.6 & 14.1 & 47.48 & 10.3 & 13.1 & 46.8 & 11.5 \\
\hline Head & 100 & 43.9 & 64.1 & 100 & 45.18 & 69.0 & 100 & 44.0 & 82.6 \\
\hline
\end{tabular}

The results of magnetic separation studies using classified materials generated by wet sieving (i.e. washing of individual fractions) are presented in Table 5. It is observed that the results are almost matching with the results of dry sieving method hence; using wet sieving technique derives no significant advantage. This also reveals that there is no surface coating of fines over coarse fractions.

Table 5. Results of dry magnetic separation of wet sieving samples.

\begin{tabular}{|c|c|c|c|c|c|c|c|c|c|}
\hline & \multicolumn{3}{|c|}{ 0.73 tesla } & \multicolumn{3}{c|}{1.00 tesla } & \multicolumn{3}{c|}{1.23 tesla } \\
\hline Size, in $\mu \mathrm{m}$ & Wt. \% & Mn \% & $\begin{array}{c}\text { Mn \% } \\
\text { recovery }\end{array}$ & $\begin{array}{c}\text { Wt. } \\
\%\end{array}$ & Mn \% & $\begin{array}{c}\text { Mn \% } \\
\text { recovery }\end{array}$ & $\begin{array}{c}\text { Wt. } \\
\%\end{array}$ & $\begin{array}{c}\text { Mn } \\
\%\end{array}$ & $\begin{array}{c}\text { Mn \% } \\
\text { recovery }\end{array}$ \\
\hline$-1000+500$ & 35.1 & 42.8 & 22.0 & 39.3 & 46.4 & 25.7 & 42.0 & 41.9 & 30.7 \\
\hline$-500+250$ & 31.8 & 43.2 & 20.1 & 32.8 & 46.7 & 21.7 & 32.6 & 44.7 & 25.5 \\
\hline$-250+150$ & 17.2 & 44.1 & 11.1 & 13.8 & 47.1 & 9.3 & 12.3 & 42.9 & 9.3 \\
\hline$-150+75$ & 15.9 & 45.6 & 10.6 & 14.1 & 47.4 & 9.5 & 13.1 & 46.4 & 10.6 \\
\hline Head & 100 & 43.9 & 63.8 & 100 & 46.7 & 66.2 & 100 & 43.5 & 76.1 \\
\hline
\end{tabular}




\subsection{Wet Magnetic Separation}

The results of wet magnetic separation at different size fractions are presented in Table 6. The effect of magnetic intensity was studied in each case. The intensity was varied from 0.73 tesla to 1.23 tesla to assess its effect on separation efficiency. The results show that the weight percent and grade of magnetic product increases with increase of magnetic intensity. Better separation is achieved at finer fraction as compared to coarser ones. The loss of $\mathrm{Mn} \%$ in non-magnetic fractions has also been reduced at higher intensity. It is possible to get a product with $42 \% \mathrm{Mn}$ by recovering $56 \%$ Mn values on an average.

Table 6. Results of wet magnetic separation at different size \& magnetic intensities.

\begin{tabular}{|c|c|c|c|c|c|c|c|c|c|}
\hline & \multicolumn{3}{|c|}{ 0.73 tesla } & \multicolumn{3}{c|}{1.00 tesla } & \multicolumn{3}{c|}{1.23 tesla } \\
\hline Size, in $\mu \mathrm{m}$ & Wt. \% & Mn \% & $\begin{array}{c}\text { Mn \% } \\
\text { recovery }\end{array}$ & $\begin{array}{c}\text { Wt. } \\
\%\end{array}$ & Mn \% & $\begin{array}{c}\text { Mn \% } \\
\text { recovery }\end{array}$ & $\begin{array}{c}\text { Wt. } \\
\%\end{array}$ & $\begin{array}{c}\text { Mn } \\
\%\end{array}$ & $\begin{array}{c}\text { Mn \% } \\
\text { recovery }\end{array}$ \\
\hline$-1000+500$ & 38.9 & 41.6 & 14.4 & 40.5 & 40.1 & 24.4 & 42.5 & 39.3 & 26.4 \\
\hline$-500+250$ & 21.5 & 42.5 & 10.8 & 18.7 & 40.7 & 20.1 & 16.6 & 40.4 & 22.3 \\
\hline$-250+150$ & 11.8 & 42.8 & 1.7 & 10.4 & 41.4 & 2.1 & 7.2 & 41.7 & 2.5 \\
\hline$-150+75$ & 27.8 & 43.1 & 4.0 & 30.4 & 45.6 & 4.6 & 33.7 & 44.0 & 5.0 \\
\hline Head & 100 & 42.5 & 30.9 & 100 & 42.7 & 51.2 & 100 & 41.3 & 56.2 \\
\hline
\end{tabular}

\section{DISCUSSION}

Mineralogical characterization of low-grade siliceous manganese ore from Bonai-Keonjhar belt indicated the presence of two dominating but contrasting phases. Pyrolusite with minor cryptomelane and hematite occur as the chief ore mineral and quartz with little kaolinite as gangue constituent. These two major phase pyrolusite and quartz differ significantly in respect of their specific gravities; 4.7 and 2.65 respectively. This difference is well demonstrated in the heavy liquid separation studies using bromoform (2.86) as the separating media. It gives an insight into the possibility of upgradation of low-grade siliceous Mn-ore based on differences in density values of constituent phases. The results of this study clearly demonstrate an upgradation of Mn-value up to $45 \%$ Mn with $97 \%$ recovery at $-150+75 \mu \mathrm{m}$ size fraction. In order to further accomplish the separation of manganese from siliceous gangue, tabling experiments were conducted. The results reveal that there is a significant increase in Mn-value (42\%) in the 
concentrate for the size fraction $-1000+150 \mu \mathrm{m}$. But an appreciable quantity of manganese is lost to middling and tailing. The size fraction below $150 \mu \mathrm{m}$ also does not give much encouraging results. As an alternative, magnetic separation technique was employed to find out the possibility of separating these two phases. Manganese minerals are para-magnetic while the siliceous gangue is non-magnetic. So magnetic Mn-minerals can easily be separated from silica. Keeping this in view, all the size fractions were subjected to both dry and wet high intensity magnetic separation processes at different magnetic intensities (0.73 tesla, 1.00 tesla and 1.23 tesla). The results reveal that in case of both dry and wet magnetic separation, the manganese grade increases with decrease in size of the particles while recovery increases by increasing the intensity. This is due to better liberation at finer size fractions. Among the different intensities studied the result at 1.00 tesla gives best separation. A magnetic product with $>46 \% \mathrm{Mn}$ and $>42 \%$ Mn can be obtained with $>69 \%$ and $>56 \%$ recovery through dry and wet magnetic separation technique respectively. The dry magnetic method gives better grade and recovery of Mn-values than the wet separation methods, so the former process may be considered for commercialization. In order to assess the impact of coating of siliceous fines on manganese minerals, which would reduce the efficiency during magnetic separation, all the size fractions were wet sieved and processed through dry magnetic separation under similar conditions as above. There is no significant change in results in comparison to the data obtained for dry sieved samples.

Thus a final magnetic product with $>46 \%$ Mn-value can be obtained from a bulk feed of 26\% $\mathrm{Mn}$ and $32 \% \mathrm{SiO}_{2}$ with $69 \%$ over all recovery by dry magnetic separation method at $-150+75$ $\mu \mathrm{m}$ size fraction and 1.00 tesla magnetic intensity. Beneficiation studied of medium grade Mnore from Chikla, Maharastra, India ${ }^{(3,4)}$ have shown that a ore having $44 \% \mathrm{Mn}$ can be upgraded to $51 \% \mathrm{Mn}$ by wet magnetic separation process. In case of the present study, upgradation of lowgrade Mn-ore ( $26 \% \mathrm{Mn}$ ) to $>45 \% \mathrm{Mn}$ by dry magnetic separation process is indeed a significant achievement due to better liberation of Mn-minerals \& gangue and dominance of pyrolusite phase.

\section{CONCLUSIONS}

The response of magnetic separation process to upgradation of a low-grade siliceous manganese ores of Bonai-Keonjhar belt, Orissa, India has opened up new vistas for utilizing such ores otherwise rejected and dumped at mine sites causing both dispersal and environmental hazards. Sincere efforts are required to recover this metal leading to value addition and zero waste mining and industrial processes. 


\section{Acknowledgements}

The authors are highly thankful to the Director, Institute of Minerals and Materials Technology, Bhubaneswar for his kind permission to publish this paper. The authors are also thankful to the Department of Science \& Technology, New Delhi, India for their financial support in the form of a project (ESS/23/VES/043/99).

\section{References}

(1) Mishra, P.P. (2005); Mineralogical and Geochemical studies on manganese ores from Roida region, Keonjhar dist, Orissa with special reference to their optimum utilization. Unpublished thesis.

(2) Indian Mineral Year Book (2003). Manganese ores, IBM publ. P. 55 (1-21)

(3) Rao. G.V; Mohapatra, B.K; and Tripathy, A.K (1988). Enrichment of the manganese content by wet high intensity magnetic separator from chikla manganese ore, India. Magnetic and Electrical Separation, v. 9, p. 69-82.

(4) Mohapatra, B.K; Rao, D.S; and Sahu, R.K. Characterisation and magnetic separation studies on chikla manganese ore, Maharastra. Ind. Min Eng. J., July 1995, p. 37-41 